\title{
GUAR GUM HYDROGEL MICROBIAL FUEL CELL USING B.MEGATERIUM
}

\author{
Sumin $\mathrm{KIM}^{1, *}$ \\ ${ }^{1}$ Winchester College, College Street, Winchester SO23 9NA, United Kingdom
}

\begin{abstract}
The main factors of a microbial fuel cell $(M F C)$ are the anode and the microorganisms around it that produce electrons. This research focuses on increasing the efficiency of a MFC in plantMFC (PMFC) or aquarium-like conditions by inoculating microorganisms that help produce electrons to the soil. Guar gum was used as a base structure as it can culture microorganisms and create a hydrogel by cross-linking with borax.[1,2] Bacillus megaterium was added to the hydrogel as it can survive under the basic conditions of borax while producing electrons. [3] Glucose was added as well to help culture the bacteria. Then, the change of voltage was observed along with the growth of B.megaterium. A compound consisting of $0.5 \%$ glucose, $1 \%$ Guar gum, $10 \%$ Borax, and B.megaterium culture medium was created with a volume ratio of 1:25:1:1 in each order. This compound will be named GGB-B. GGB-B was able to keep its shape as a hydrogel along with a voltage increase of $250 \mathrm{mV}$ compared to control due to the stable growth of B.megaterium. $100 \mathrm{~g}$ of GGB-B was placed inside a beaker and was covered with aquarium soil. Two goldfishes (Carassius auratus) were added. Voltage, $\mathrm{pH}$, and the health of goldfishes were observed for 9 days. The result was approximately a $150 \mathrm{mV}$ increase in voltage compared to control (tap water). $\mathrm{pH}$ decrease was about 1.3, showing a $\mathrm{pH}$ of 6.12. There was no change in the goldfishes, and the GGB-B under the aquarium soil fused with the soil as it disintegrated. Therefore, when electron-producing microorganisms such as B.megaterium are added to guar gum, the microorganisms would slowly spread over the soil, thereby increasing the efficiency of MFC. This could also apply to PMFC and aquarium-like conditions as well.
\end{abstract}

Keywords: Guar gum hydrogel, microbial fuel cell, b.megaterium.

\section{Introduction}

A microbial fuel cell (MFC) is functioned when microorganisms culture by consuming glucose or other similar nutrients. During this process, microorganismsin the anode produce electrons [1]. Therefore, the role of microorganisms present in the anode is critical to the fuel cell, and those who have this role are mostly anaerobic [1]. These anaerobic microorganisms require a mud-like evironemnt to culture. Since it is difficult to make MFCs under this condition, the use of aerobic microorganisms is required. Also, when a microorganism that can improve the fuel cell's efficiency is inserted into the soil, the efficiency might fall over time as the microorganism leave the soil.

Therefore, to culture a microorganism to soil, it must not leave the soil over time. To fullfill this purpose, Guar gum hydrogel was used. Guar gum reacts with Borate ions to crosslink into a hydrogel form which not only allows it to be B.meagterium's carrier [2,3] but also allows 
it to be a nutrient source for microorganisms as Guar itself is composed of polysaccharide connections of mannose and galactos [4].

B.megaterium, an aerobic microorganism which is gram positive, was selected to be cultured into the Guar hydrogel. B.megaterium produces acetate to release electrons at the anode [5], B.megaterium was chosen as it can survive under the alkali conditions of Borax which is treated to Guar and therefore can be cultured in guar gum hydrogel $[1,6]$.

In this experiment, B.megaterium will be cultured in Guar gum hydrogel to find out if it could be applied to soil under water conditions such as PMFCs or Aquariums and to find out possible methods of increasing the efficiency of the MFC thereby improving the voltage.

\section{Method}

\section{The culture of B.megaterium in Guar Gum}

The efficiency of Guar gum for B.megaterium culture and the growth of B.megaterium under Guar gum + Borax ion hydrogel condition was checked. 1\% Guar gum (UHV-66, Haji dossa nutralum ltd from Pakistan) was used after being sterilized inside an Autoclave at $121{ }^{\circ} \mathrm{C}$, for 15 minutes. Then, $1 \%$ Guar gum solution with volumes of each $50 \mu \mathrm{L}, 100 \mu \mathrm{L}, 150 \mu \mathrm{L}$ was added to $1 \mathrm{~mL}$ NB (Nutrient Broth). B.megaterium (KTCT 1098) $100 \mu \mathrm{L}$ was inoculated and was cultured under $30^{\circ} \mathrm{C}$ for 2 days inside an incubator.

The cultured solution's absorbance was measured using a Spectrophotometer (UV-Vis spectrum Jenway 7305) from 630nm wavelength. Then, the effect of Borax (Duksan, Sodium tetraborate, Decahydrate), which is used when turning guar gum into hydrogel, on B.was checked. $100 \mu \mathrm{L}$ of B.megaterium culture medium was added to NB $1 \mathrm{~mL}$ and $5 \%$ Borax solution of each $40 \mathrm{uL}$ and $50 \mathrm{uL}$ was added. Absorbance was measured.

\section{Culutre of B.megaterium in guar gum hydrogel}

B.megaterium was successfully cultured in both $1 \%$ Guar gum solution and 5\% Boax solution and therefore a hydrogel was composed using the same conecntrations to culture B.megaterium. $1 \mathrm{~mL}$ B.megaterium was added to $25 \mathrm{~mL}$ of $1 \%$ Guar gum solution and $5 \%$ Borax $1 \mathrm{~mL}$ was treated to create a hydrogel. $500 \mu \mathrm{L}$ of this hydrogel was dropped into NA(Nutrient Agar) to confirm successful culturing under hydrogel conditions.

Then, 5\% Boarx solution was added to $1 \%$ Guar gum to create a hydrogel and B.megaterium $1 \mathrm{mLwas}$ inoculated to check if B.megaterium was cultured by spreading out.

\section{The oxidation of B.megaterium}

Production of electrons by B.megaterium on the anode was tested. $1 \%$ Agar and $\mathrm{NaCl}$ was binded inside a plastic tube to create a salt bridge. This salt bridge was connected between two conical tubes. On one side, B.megaterium solution was added and NB solution was added to the other. $\mathrm{Cu}, \mathrm{Zn}$ electrodes were added like the picture below and voltage was measured. Then, $\mathrm{Cu}$ and $\mathrm{Zn}$ was each placed into NB solution and B.megaterium solution in an opposite manner to measure the voltage. Both electrodes were placed inside the B.megaterium solution to measure voltage.

\section{The difference of B.megaterium growth on dependence to glucose treatment on guar gum hydrogel}

When glucose is treated to guar gum hydrogel, B.megaterium can grow faster thereby improving the voltage. However, when $3 \mathrm{~g}$ of Glucose was treated to $20 \mathrm{~mL} 1 \%$ Guar gum solution, the cross-link reaction did not occur. This was because Glucose reacted with some of the Borate ions bonded to Guar gum which lead to the breaking of crosslinks [7]. Therefore, glucose conecentration was manipulated to find a certain concentration of glucose that could maintain a certain viscosity and voltage. 

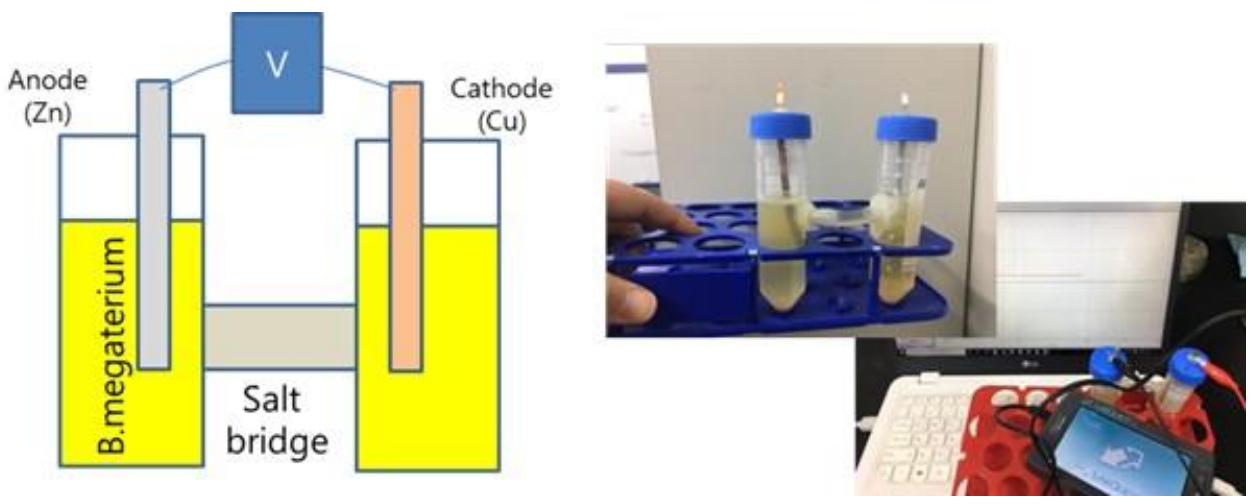

Fig. 1. Voltage measured using salt bridge

Glucose was added to $25 \mathrm{~mL}$ of $1 \%$ Guar gum solution to make solutions of concentrations $0 \%, 0.2 \%, 0.5 \%$, and $1 \%$, Then, $1 \mathrm{~mL} \mathrm{B.megaterium} \mathrm{was} \mathrm{inoculated} \mathrm{and} 1 \mathrm{~mL} \mathrm{5 \%}$ Borax was added. The complexd of Guar gum, Glucose, Borax, and B.megaterium will now be mentioned as GGB-B from now on. The complex was cultured inside an incubator for 2 days and voltage, viscosity, and $\mathrm{pH}$ was measured.

In this experiment, B.megaterium released acetate using glucose and guar gum was hydrolysed [8]. Therefore, the complex lost viscosity and turned into a liquid form. In order to raise the viscosity, Glucose solutions of concentrations $0 \%, 0.2 \%, 0.5 \%, 1 \%$ was added to Borax solutions of conecntrations $5 \%$ and $10 \%$ and the spreading of the GGB-B hydrogels were measured over 5 minutes. The voltage for each case was measured to look for the most appropriate concentration of Borax and glucose. Along to this, samples of each hydrogel was taken using loops and then streaked onto NA culture mediums to check for the growth of B.megaterium.

The variation of GGB-B voltage, $p H$, and viscosity depending on temperature and buffer treatment

GGB-B was created with $10 \%$ Borax solution and $0.5 \%$ solution, which showed appropriate spreading and voltage accordingly to the previous experiment. Then, to prevent GGBB's $\mathrm{pH}$ turning acidic, buffer was suggested to be treated. The buffer was created by mixing 0.2 $\mathrm{M} \mathrm{Na}_{2} \mathrm{HPO}_{4} \cdot 12 \mathrm{H}_{2} \mathrm{O}$ (Duksan) and $0.2 \mathrm{M}$. $\mathrm{NaH}_{2} \mathrm{PO}_{4} \cdot 2 \mathrm{H}_{2} \mathrm{O}$ (Sigma) to create solutions each of $\mathrm{pH} 7$, and 8 . Then, $1 \mathrm{~mL}$ each of $\mathrm{pH} 7$ and $\mathrm{pH} 8$ solution was added to GGB-B. The complex was cultured under temperatures of $37^{\circ} \mathrm{C}$ and room temperature (about $20^{\circ} \mathrm{C}$ ). $\mathrm{pH}$ and voltage was measured.

\section{Appliance to aquariums}

The possibility of applying GGB-B to aquarium-like conditions was confirmed.

The ratio of GGB-B was $1 \%$ Guar gum: $0.5 \%$ Glucose: $10 \%$ Borax: B.megaterium culture medium $=25: 1: 1: 1$ and a total of $100 \mathrm{~mL}$ was created. The created 100g GGB-B was placed into a beaker and aquarium soil (Neo soil compact, Aquario) 200g was added on it. Finally, two goldfishes and $1 \mathrm{~L}$ of water was added with an oxygen supply. Voltage, $\mathrm{pH}, \mathrm{COD}, \mathrm{DO}$, and the survival of goldfishes were checked from day 1 to day 9 .

To prevent water contact with the $\mathrm{Zn}$ anode and only allow contact with the GGB-B containing soil, the anode was placed inside a conical tube and the anode was only exposed for the height of the soil. 

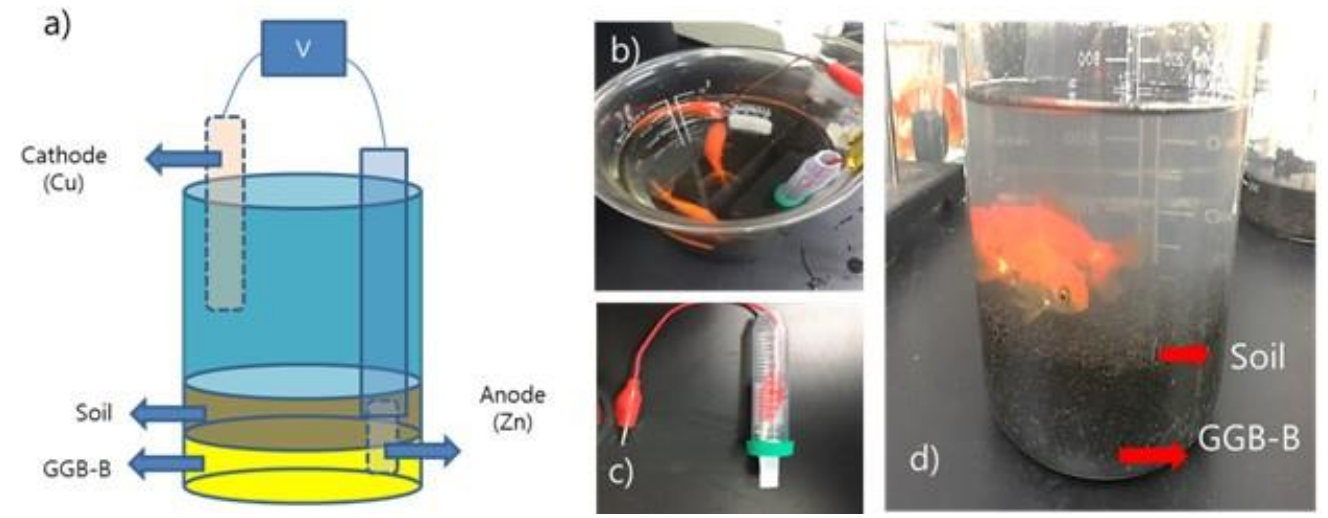

Fig. 2. GGB-B and goldfish treatment a) connection between GGB-B and anode, b) goldfish observation; c) Anode used in experiment d) after three days

\section{Results and Discussion}

\section{The change of B.megaterium under Guar gum and borax conditions}

Guar gum's role as a nutrient for B.megaterium growth was checked, as well as B.megaterium's survival under alkali Borax. As a result, the increase of guar amount by $50 \mu \mathrm{L}$ resulted in B.megaterium's absorbance increase. At $150 \mu \mathrm{L}$ of guar, the absorbance increased by 5 times compared to control

When borax's influence on B.megaterium growth was checked, there was only minimal change in absorbance depending on borax's presence.

Therefore, a conclusion that B.megaterium can be cultured under guar gum Borax hydrogel condition was derived.

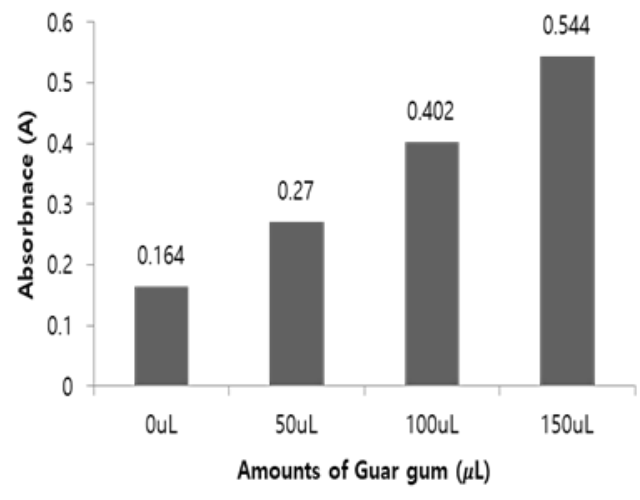

a)

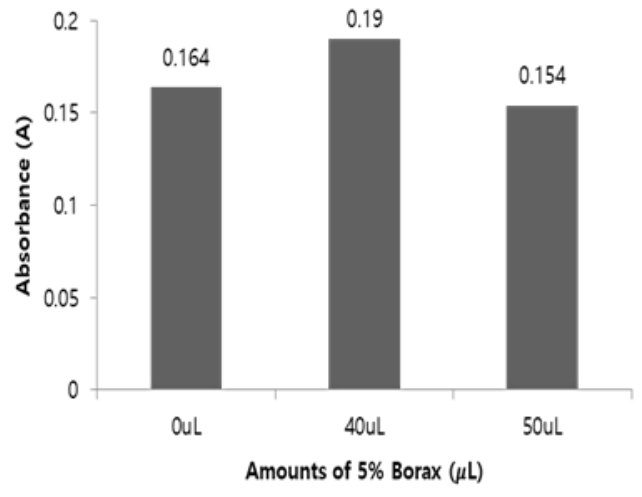

b)

Fig. 3. Absorbance of: a) B.Megaterium in Guar gum; b) B.megaterium in Borax

\section{The change of B.megaterium under Guar gum - Borax hydrogel conditions}

It was checked if B.megaterium could be cultured when a hydrogel was created by adding B.megaterium to Guar gum and Borax was mixed. First, when a hydrogel was created with guar gum and borax and B.megaterium was inoculated, the spreading of bacteria was observed as in Fig. a). Also, when guar gum, B.megaterium, and Borax was mixed and treated on NA culture medium, it could be observed that B.megaterium growed around the speraded region. Therefore, the culture of B.megaterium by mixing guar gum and borax was proved to be possible. 

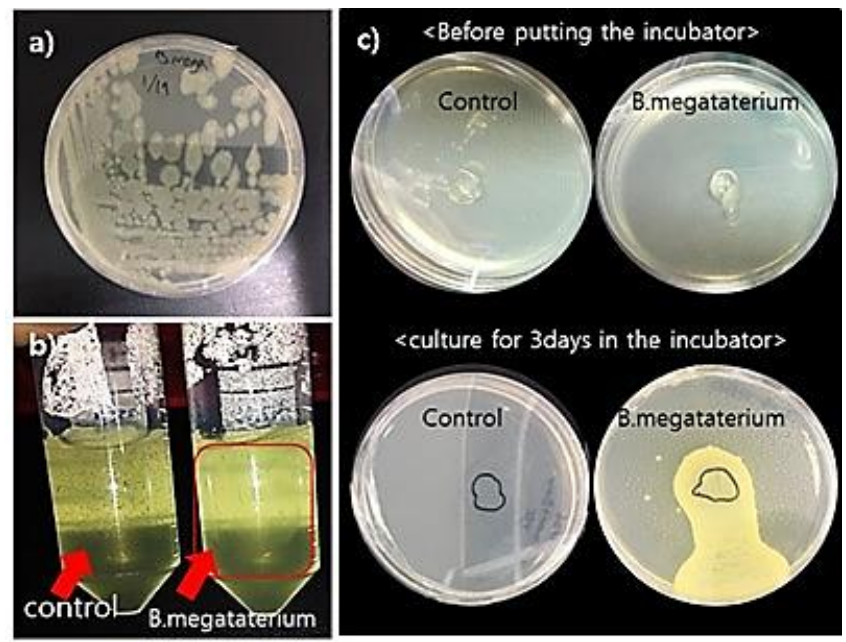

Fig. 4. Growth of B. megaterium a) B.megaterium colony; b) B.megaterium in Guar hydrogel; c) B.megaterium cultured in Guar hydrogel

\section{The voltage change due to oxidation of B.megaterium}

To check if B.megaterium produces electrons, the $\mathrm{Zn}$ electrode was added to B.megaterium, and the $\mathrm{Cu}$ electrode was added to NB and voltage was measured. As a result, placing $\mathrm{Zn}$ electrode in B.megaterium and $\mathrm{Cu}$ electrode in NB had a higher voltage compared to placing $\mathrm{Zn}$ electrode into $\mathrm{NB}$ and $\mathrm{Cu}$ electrode into B.megaterium and placing $\mathrm{Zn}$ and $\mathrm{Cu}$ electrodes both into B. Megaterium each by $0.059 \mathrm{~V}$ and $0.022 \mathrm{~V}$. This result reconfirms that placing the $\mathrm{Zn}$ anode in $\mathrm{B}$. megaterium causes a rise in voltage.

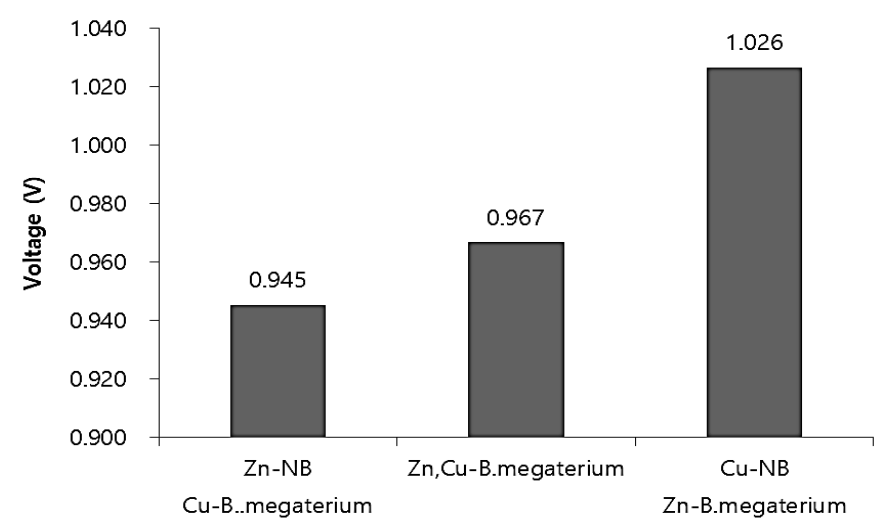

Fig. 5. The change of voltage of the solution with $\mathrm{Cu}$ and $\mathrm{Zn}$ electrodes added

\section{The change of Guar hydrogel depending on glucose concentration}

$1 \mathrm{~mL}$ of $5 \%$ Borax and $1 \mathrm{~mL}$ of B.megaterium was added to $25 \mathrm{~mL} 1 \%$ Guar gum and Glucose was added each with concentration $0.2 \% \sim 1 \%$. After 2 days of culturing, the viscosity, $\mathrm{pH}$, and voltage of each GGB-B, a mixture of Guar gum, Glucose, Borax and B.megaterium, was measured. The viscosity of GGB-B which was placed inside the incubator was lost. This is because B.megaterium releases acetate using glucose which results in the hydrolysis of guar gum, which thereby weakens the crosslink bond between guar gum and borax. The voltage of GGB-B from the incubator increased as the concentration of glucose increased, but $\mathrm{pH}$ decreased as glucose concentration increased. 


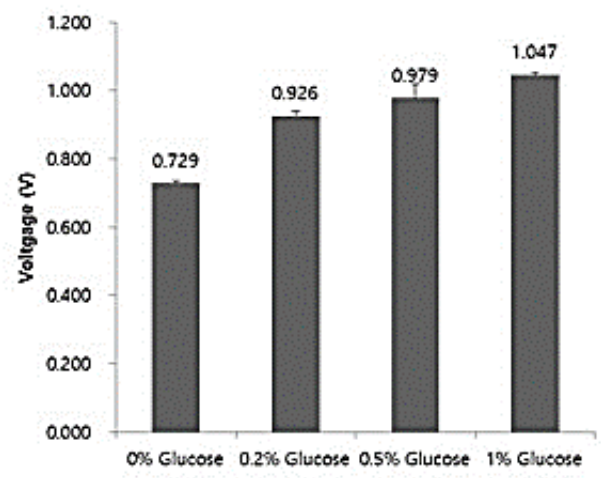

a)

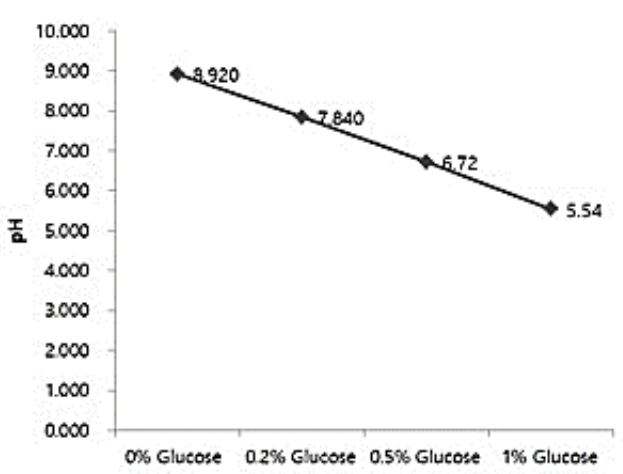

b)

Fig. 6. a) voltage change and b) $\mathrm{pH}$ change caused by change of glucose concentration

However, the increase of glucose concentration could result in the weakening of GGBB crosslink bonds so an experiment was done by trying two Borax concentrations of 5\% and $10 \%$. When viscosity was measured by observing the spread of GGB-B on a petri dish over 5 minutes, the GGB-Bs that kept their original shape best were GGB-B composed of $10 \%$ Borax and $0.2 \%$ Glucose and GGB-B composed of $10 \%$ Boranx and $0.5 \%$ Glucose.

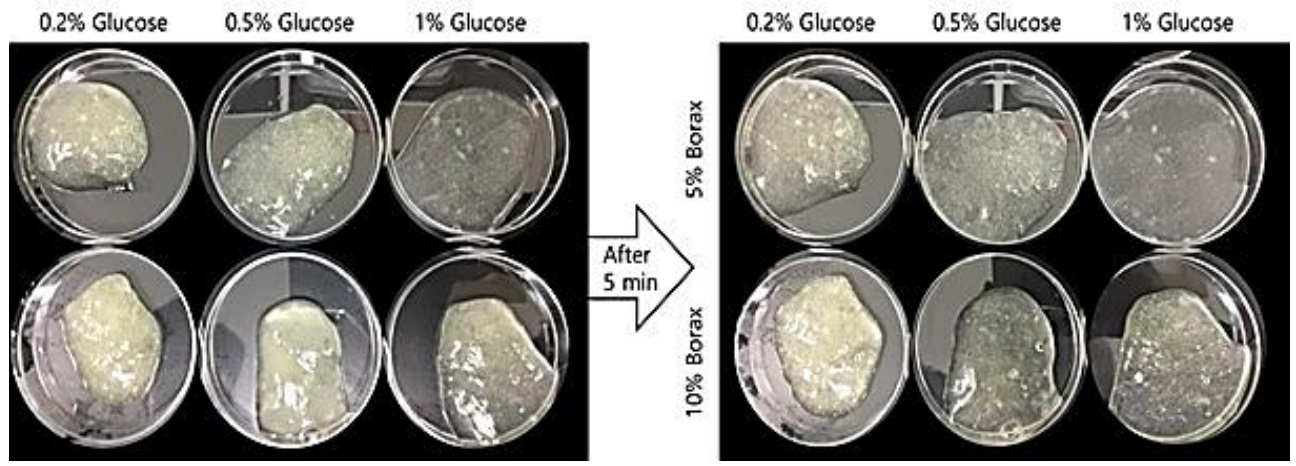

Fig. 7. Change of viscosity of Guar gum hydrogel by concentrations of glucose and Borax

When voltage was measured for these GGB-Bs, the voltage was higher $1 \%$ Glucose compared to $0.2 \%$ and $0.5 \%$ Glucose, and $1 \%$ Glucose and 5\% Borax mixture had higher voltage compared to $1 \%$ Glucose and $10 \%$ Borax. However, in overall, the voltage did not show great variance.

\section{The change of voltage, $p H$, and shape of GGB-B depending on temperature and buffer conditions}

When B.megaerium was cultured at an excessive speed, the viscosity of GGB-B decreased, making it harder to treat inside soil. Therefore, buffer was added to control the $\mathrm{pH}$ of GGB-B, and the shape, voltage, and $\mathrm{pH}$ of GGB-B was observed under temperatures of $20^{\circ} \mathrm{C}$ and $37^{\circ} \mathrm{C}$.

When the shape was observed 3 days later, GGB-B which were under $0.2 \%$ Glucose and $0.5 \%$ Glucose $+\mathrm{pH} 8$ buffer conditions which were placed in $37^{\circ} \mathrm{C}$, the GGB-B bond was not maintained and it could not be taken out of their conical tubes, like the picture below. The other two GGB-Bs in $37^{\circ} \mathrm{C}$ did not maintain their shape. The GGB-Bs placed in $20^{\circ} \mathrm{C}$ kept their shape apart from the GGB which was composed of $0.5 \%$ Glucose. What is peculiar about 
the $0.5 \%$ Glucose GGB-B is that every GGB-B apart from this $0.5 \%$ Glucose GGB-B released water. The reason seemed to be buffer causing more bonds within GGB-B which released water inside.

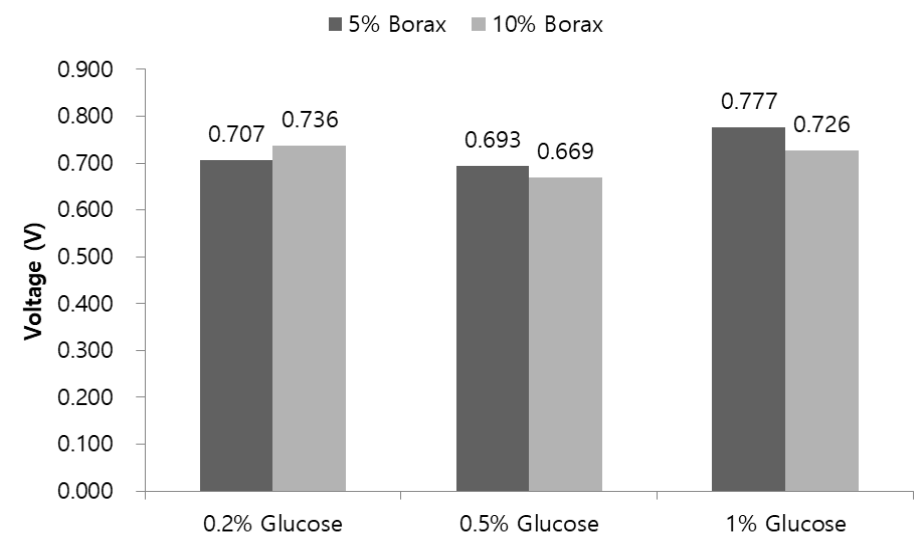

Fig. 8. Hydrogel voltage change by glucose and Borax concentration

a)

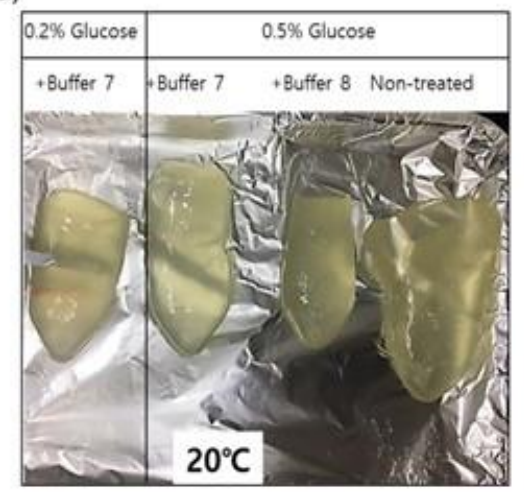

b)

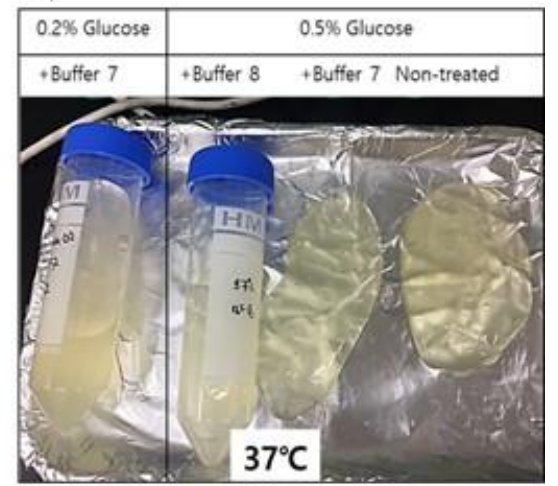

Fig. 9. Change of GGB-B: a) $20^{\circ} \mathrm{C}$ condition b) $37^{\circ} \mathrm{C}$ condition

The change of GGB-B was observed under water sediment conditions. GGB-B was cultured for 3 days under $20^{\circ} \mathrm{C}$ and placed inside a conical tube with $20 \mathrm{~mL}$ water and the amount of water absorbed by GGB-B and shape of GGB-B was observed. A a result, $0.5^{\circ} \mathrm{C}$ Glucose GGB$\mathrm{B}$ did not absorb water but on other three conditions, GGB-B absorbed $3 \mathrm{~mL} \sim 3.5 \mathrm{~mL}$ of water. It seems that the water released by the buffer was absorbed back again.

The voltage change of GGB-B was highest when cultured under $37^{\circ} \mathrm{C}$ for 5 days. The second highest was when cultured under $20^{\circ} \mathrm{C}$ for 5 days, and $0.5 \%$ Glucose GGB-B was measured higher compared to other conditions.

$\mathrm{pH}$ was opposite to voltage; it was lowest when GGB-B was cultured under $37^{\circ} \mathrm{C}$ for 5 days, and highest when cultured under $20^{\circ} \mathrm{C}$ for 3 and 5 days. 


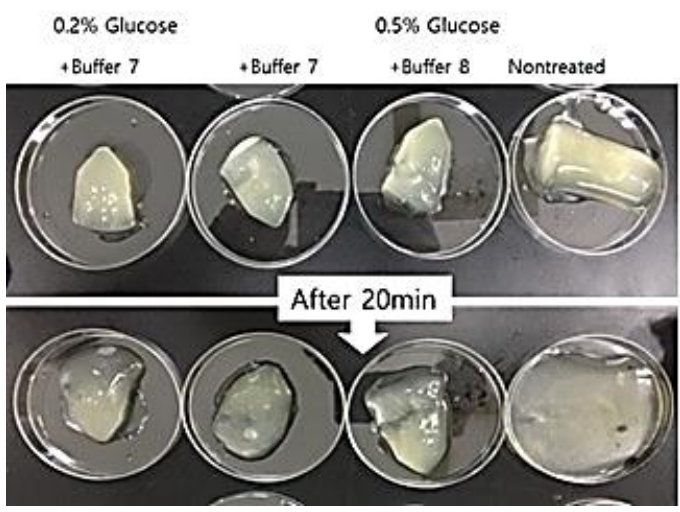

a)

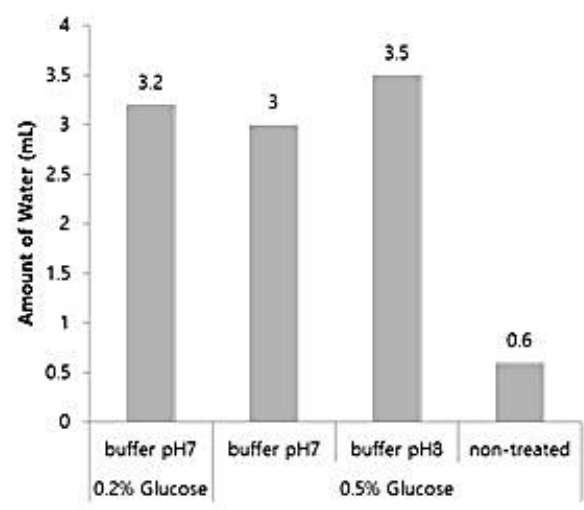

b)

Fig. 10. Buffer-treated GGB-B: a) viscosity change; b) water absorbance

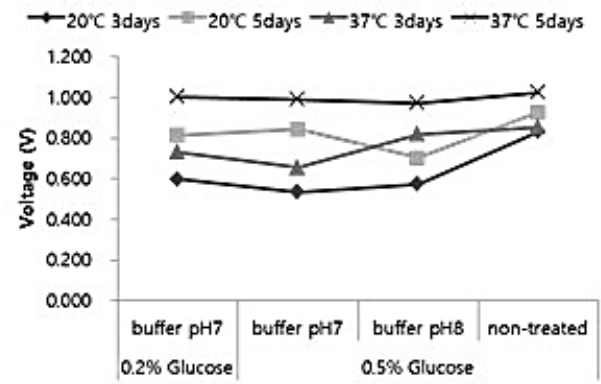

a)

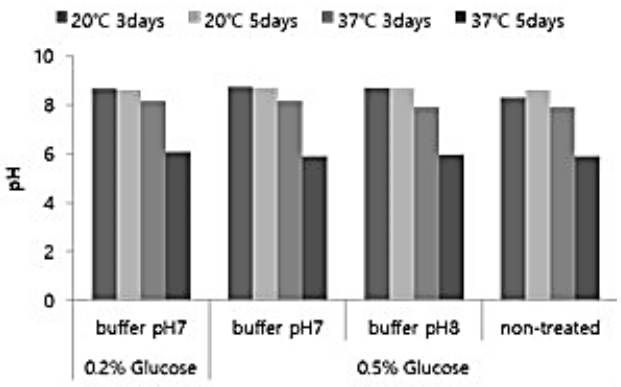

b)

Fig. 11. GGB-B by different buffer and temperature conditions: a) voltage change; b) pH change

Therefore, GGB-B that maintained its shape along with high voltage, high $\mathrm{pH}$ and water maintenance was $0.5 \%$ Glucose GGB-B without buffer under $20^{\circ} \mathrm{C}$. In aquarium conditions, the water temperature does not exceed $20^{\circ} \mathrm{C}$, so following experiments were done under this condition.

\section{The changes of voltage, water quality, and goldfishes in a GGB-B treated aquarium}

After observing the beaker for 9 days after treating GGB-B, the dissolved GGB-B under the aquarium soil left the soil and made the water opaque. However, there was no special change in the goldfishes.

The DO of water quality was similar to the control due to the use of oxygen supply by $8 \sim 10 \mathrm{ppm}$, and COD was higher than control by 4ppm as 10ppm due to GGB-B dissolving under aquarium soil.

The voltage increased constantly in the beaker treated with GGB-B and goldfishes from $1.007 \mathrm{~V}$ to $1.101 \mathrm{~V}$ after 9 days, and when compared to control, there was a difference of $0.097 \mathrm{~V} \sim 0.191 \mathrm{~V}$ as shown in fig 12 . The beaker with only GGB-B showed no voltage change until day 2, but voltage increased after 7 days and the voltage change was similar to that of with goldfish.

While the control had a $\mathrm{pH}$ of 7.42 7.62, the beaker with GGB-B's $\mathrm{pH}$ turned weak acid, and GGB-B with goldfish had a slightly lower $\mathrm{pH}$. The water quality $\mathrm{pH}$ change seems to be due to B.megaterium releasing acetate by dissolving Glucose and Guar gum, and this acetate hydrolysing Guar gum, thereby accelerating the dissolving of GGB-B. 


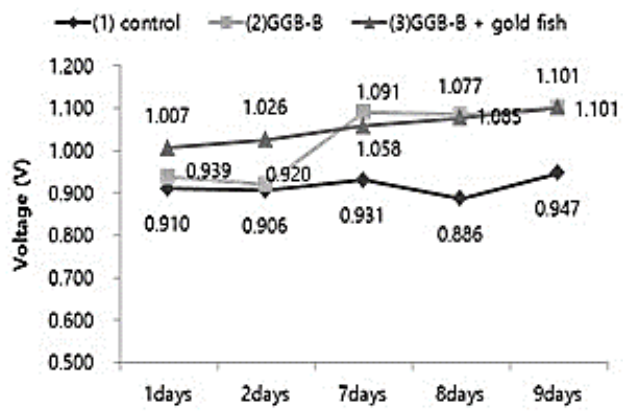

a)

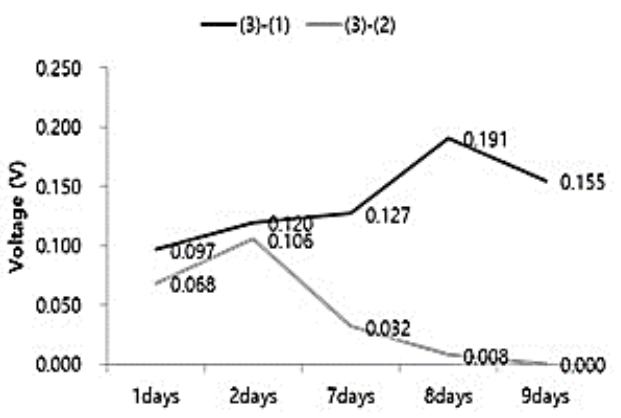

b)

Fig. 12. Voltage change: a) GGB-B and GGB-B+goldfish; b) control sample

Table 1. $\mathrm{pH}$ chang in GGB-B and GGB-B + gold fish

\begin{tabular}{lccc}
\hline & (1) control & (2) GGB-B & (3) GGB-B + gold fish \\
\hline 1 days & 7.62 & 6.93 & 5.98 \\
2 days & 7.57 & 6.54 & 5.88 \\
7 days & 7.52 & 6.83 & 6.07 \\
8 days & 7.47 & 6.68 & 6.14 \\
9 days & 7.42 & 6.54 & 6.57 \\
\hline
\end{tabular}

Overall, when GGB-B is treated to soil, the Glucose and B.megaterium consisting the guar hydrogel causes an increase in voltage and the production of acetate can dissolve guar, which then spreads the voltage-increasing microorganism widely around the sediment, increasing the efficiency of microbial fuel cells such as PMFC.

\section{Conclusion}

Guar gum and hydrogel was utilized as a way to increase efficiency of microbial fuel cells in soils of PMFC or Aquarium conditions by adding bacteria. When $1 \%$ guar gum solution was added to B.megaterium, the absorbance increased, and the bacteria was well-cultured in 5\% borax solution which is crosslinked to Guar gum in hydrogel state as well. When B.megaterium was inoculated into Guar gum hydrogel, B.megaterium was successfully cultured around the hydrogel again.

To help the culture of B.megaterium, Glucose was added to Guar gum to create a GGB-B (Guar gum+Glucose +Borax+B.megaterium) complex. Glucose can react with borate ions which are cross linked to Guar gum and therefore can make the bonds inside the hydrogel softer. However, under high concentrations, the bonds can be broken completely. Also, when GGB-B was incubated under $20^{\circ} \mathrm{C}$ and $37^{\circ} \mathrm{C}$, GGB-B under $37^{\circ} \mathrm{C}$ did not maintain its shape as a solid. This is because the acetate released by B.megaterium hydrolyses guar gum. Under $20^{\circ} \mathrm{C}$, B.megaterium was grown at a slower speed, which helped the hydrogel maintain its shape.

Therefore using the conditions where the shape was maintained with an appropriate level of voltage of $0.975 \mathrm{~V}$, (1\% Guar gum $25 \mathrm{~mL}, 0.5 \%$ Glucose $1 \mathrm{~mL}$, Borax $1 \mathrm{~mL}$, B.megaterium $1 \mathrm{~mL})$ GGB-B was created and then treated to aquarium soil. After measuring the voltage for 9 days, compared to 2 days, the voltage increased by about $0.094 \mathrm{~V}$, and $0.097 \mathrm{~V} \sim 0.191 \mathrm{~V}$ compared to control. pH was slightly acidic compared to control, and GGB-B slowly dissolved causing the water to be less transparent.

In conclusion, microorganisms that increase battery efficiency can be treated to soil under water using GGB-B, and the dissolving of GGB-B can help the spread of microorganisms over 
to soil itself. By manipulating the concentration of Guar gum and Glucose, the dissolving rate of GGB-B is also manipulatable which can help inoculating microorganisms to the soil at a certain rate, which can be applied to PMFC or sediments in aquarium conditions.

\section{References:}

[1] Song, H.L., Ying Z. and Jie L. Electron transfer mechanisms, characteristics and applications of biological cathode microbial fuel cells-A mini review. Arabian Journal of Chemistry, 2019, 12(8) pp. 2236-2243.

[2] Hongbo, T. et al. Preparation and property of crosslinking guar gum. Polymer Journal, 2012, 44(3), pp. 211-216.

[3] Kesavan, S. and Robert K. and Prud'Homme, K. Rheology of guar and (hydroxypropyl) guar crosslinked by borate. Macromolecules, 1992, 25(7), pp. 2026-2032.

[4] Jain, R., Anjaiah, V. and Babbar, S. B. Guar gum: a cheap substitute for agar in microbial culture media. Letters in Applied Microbiology, 2005, 41(4), pp. 345-349.

[5] Yoganathan, K. and Ganesh, P. Electrogenicity assessment of Bacillus subtilis and Bacillus megaterium using microbial fuel cell technology. Int. J. Appl. Res., 2015, 1(13), pp. 435438.

[6] Parka, G.T. and Son, H.J. Keratinolytic activity of Bacillus megaterium F7-1, a featherdegrading mesophilic bacterium. Microbiological Research, 2009, 164(4), pp. 478-485.

[7] Qingzhou, C., Muscatello, M.M.W. and Asher, S.A. Photonic crystal borax competitive binding carbohydrate sensing motif. Analyst, 2009, 134(5), pp. 875-880.

[8] Suarez, C.A.G. et al. Assessment of the metabolism of different strains of Bacillus megaterium. Brazilian Archives of Biology and Technology, 2012, 55(4), pp. 485-490.

Received: March 30, 2021

Accepted: May 01, 2021 